\title{
ÉPOCAS, TIPOS DE ESTACA E SUBSTRATOS NA PROPAGAÇÃO DO PINHÃO MANSO
}

\author{
Erica Rodrigues Moreira ${ }^{1}$, Aparecida Conceição Boliani ${ }^{2}$, Maximiliano Kawahata
} Pagliarini $^{3}$, Danilo Marcelo Aires dos Santos ${ }^{4}$, Flávia Aparecida de Carvalho Mariano Nasser $^{5}$, Enes Furlani Junior ${ }^{2}$

\footnotetext{
${ }^{1}$ Bolsista Petrobrás Biocombustível, doutoranda em Sistema de Produção pela Universidade Estadual Paulista (UNESP), Faculdade de Engenharia, Câmpus de Ilha Solteira - SP. E-mail: ermoreira01 @ gmail.com .

${ }^{2}$ Docente do Departamento de Fitotecnia, Tecnologia de Alimentos e Sócio Economia - Universidade Estadual Paulista (UNESP), Faculdade de Engenharia, Câmpus de Ilha Solteira - SP

${ }^{3}$ Doutor em Sistema de Produção, Universidade Estadual Paulista (UNESP), Faculdade de Engenharia, Câmpus de Ilha Solteira - SP.

${ }^{4}$ Docente na Universidade Estadual do Tocantins, Palmas - TO.

${ }^{5}$ Pós doutoranda em Pós colheita e Tecnologia de Alimentos no Departamento de Horticultura, Universidade Estadual Paulista (UNESP), Faculdade de Ciências Agronômicas, Câmpus de Botucatu - SP.
}

RESUMO: O pinhão manso (Jatropha curcas L.) é uma planta que tem sementes com alto teor de óleo e se destaca na produção de biodiesel. Como ainda está em processo de melhoramento, uma solução para o problema da desuniformidade genética é a reprodução assexuada. Esse método facilita o trabalho do melhorista, pois, uma vez identificada uma planta considerada superior, ela pode ser propagada, mantendo a sua característica genética. Desta forma, objetivou-se com este trabalho verificar a época de coleta, tipos de estaca e substratos, na propagação do pinhão manso. $\mathrm{O}$ delineamento experimental utilizado foi inteiramente casualizado em esquema fatorial $3 \times 3$ (substrato $\times$ estaca) totalizando 9 tratamentos com 3 repetições, sendo que cada unidade experimental foi composta por 10 estacas. Para efeito de comparação das épocas foi realizada análise conjunta. Foram utilizadas como estacas: ponteiro, parte mediana e basal, com aproximadamente $20 \mathrm{~cm}$ de comprimento. $\mathrm{O}$ estaqueamento foi feito em jardineiras plásticas pretas, contendo como substratos: composto orgânico comercial (Bioplant ${ }^{\circledR}$ ), vermiculita média expandida e areia grossa lavada. As características avaliadas foram: porcentagem de estacas vivas e enraizadas, número de brotos e número de folhas por estaca, massa fresa e massa seca da parte aérea e das raízes. Os resultados permitiram concluir que a melhor época para a propagação do pinhão manso é agosto; e o uso de estacas da parte basal e dos substratos: vermiculita e composto orgânico comercial $\left(\right.$ Bioplant $\left.^{\circledR}\right)$ foram eficientes para produção de mudas de pinhão manso.

Palavras-chave: Jatropha curcas L. Biodiesel. Enraizamento. Vermiculita. Areia.

\section{TIME, TYPE OF CUTTING, AND SUBSTRAT IN PROPAGATION OF PHYSIC NUT}

ABSTRACT: Physic nut (Jatropha curcas L.) is a plant that has seeds with high oil content and stands for biodiesel production. As is still process improvement, asexual reproduction is 
the solution to the problem of desuniformity genects. This method is facilitates the breeders work because, once identified a plant considered superior, it can be propagated, maintaining its genetic characteristics. Thus, the study aimed to verify the collection time, type of cutting and different substrates on propagation of physic nut. The experimental design used was completely randomized, in factorial scheme $3 \times 3$ (substrate $\mathrm{x}$ cutting), totaling 9 treatments with 4 repetition, each experimental unit was composed by 10 cuttings. For comparison period was performed joint analysis. Was used as cuttings: pointers, median and basal part, with along $20 \mathrm{~cm}$ length. The staking was done in black vase plastic vase, containing as substrates: commercial organic compound (Bioplant ${ }^{\circledR}$ ), expanded vermiculite and sand washed. The characteristics analyzed were: percentage of survival cuttings and rooting, number of shoots and number of leaves for cutting, fresh and dry shoot and root. The results showed that the best time for the propagation of physic nut is August, and the use of cuttings from the basal position and the use substrates commercial organic compound (Bioplant ${ }^{\circledR}$ ) and vermiculite showed up for efficient production of physic nut seedlings.

Key words: Jatropha curcas L. Biodiesel. Rooting. Vermiculite. Sand.

\section{INTRODUÇÃO}

Com a iniciativa do Programa Brasileiro de Biodiesel, o pinhão manso (Jatropha curcas L.), uma planta da família Euphorbiaceae, foi incluído como alternativa de matéria prima, por ser uma planta rústica, baseando-se também na porcentagem de óleo que pode chegar aos $40 \%$, uma produção estimada em duas toneladas de óleo por hectare e baixo custo de produção (SATURNINO et al., 2005).

Para a concretização da produção de biodiesel em grande escala, é preciso grandes produções de oleaginosas com alto potencial de produção de óleo por hectare. Assim, o pinhão manso reúne várias características que a tornam uma ótima opção para ser adotada como uma das alternativas de produção de biodiesel (NUNES, 2007).

A utilização de métodos propagativos facilita o trabalho do melhorista, pois, uma vez identificado uma planta considerada superior, ela pode ser propagada, mantendo a sua característica genética. Segundo Severino et al. (2007) o pinhão manso não passou por processo de melhoramento, sendo a propagação por estaquia, utilizada para diminuir a desuniformidade genética, além de ser um método mais simples e com facilidade na obtenção e transporte. Os mesmos autores ainda citam que quando utilizada a estaquia, o enraizamento inicia-se rapidamente, dispensando tratamento com hormônios e o florescimento ocorre seis meses após o plantio. Além disso, a propagação de estacas é a geração de indivíduos idênticos geneticamente.

$\mathrm{Na}$ propagação por estaquia, para que o processo de enraizamento tenha sucesso, necessita-se da escolha de um substrato apropriado, o qual deve possuir qualidades que auxiliem a iniciação radicial nas estacas, proporcionando suporte da estaca durante o 
enraizamento (PAIVA; GOMES, 1993). Essa escolha depende da espécie, tipo da estaca e estação do ano, porém em todos os casos o substrato deve proporcionar umidade, facilidade de trocas gasosas e penetração das raízes, sendo relativamente livre de contaminações (JANICK, 1966).

A produção de mudas em substratos é uma técnica que apresenta vantagens, como a de exercer função de solo, fornecendo sustentação, nutriente, água e oxigênio à planta. Para mudas de pinhão-manso, Paulino et al. (2011) constataram que as propriedades físicas do substrato são essenciais para o pleno desenvolvimento das mudas, pois o cultivo de plantas em recipientes limita o desenvolvimento do sistema radicular, influenciando.

De acordo com Fernandes e Corá (2001) a utilização de substratos específicos, com características mais adequadas a uma determinada cultura promove melhorias no desenvolvimento da planta, redução do tempo de cultivo e custo final do produto.

Assim, devido à importância da cultura para a produção de biodiesel desenvolveu-se este trabalho com o objetivo de estudar a época, o tipo de estacas e os substratos para a produção de mudas de pinhão manso.

\section{MATERIAL E MÉTODOS}

O experimento foi realizado na Faculdade de Engenharia da Universidade Estadual Paulista (UNESP), Campus de Ilha Solteira, em casa de vegetação tipo Pad \& Fan, com temperatura média de $25^{\circ} \mathrm{C}$ e umidade relativa de $60 \%$, em duas épocas: agosto (inverno) de 2011 e março (outono) de 2012. O material vegetal foi retirado de plantas matrizes com 2 anos de idade, oriundo da Fazenda de Ensino, Pesquisa e Extensão (FEPE), localizada em Selvíria - MS. As plantas matrizes na primeira época (agosto) estavam em período de repouso vegetativo e na segunda época (março) em pleno florescimento.

Os tratamentos utilizados foram constituídos da combinação de três tipos de estacas e três tipos de substratos. Foram utilizadas estacas: de ponteiro, parte mediana e basal com aproximadamente $20 \mathrm{~cm}$ de comprimento. $\mathrm{O}$ estaqueamento foi feito em jardineiras de polietileno com dimensões de $42 \times 14 \times 14 \mathrm{~cm}$ (comprimento x largura x profundidade), preenchidas com os seguintes substratos: composto orgânico comercial (Bioplant ${ }^{\circledR}$ ), vermiculita de textura média e areia grossa lavada. $\mathrm{O}$ experimento foi irrigado três vezes ao dia $(6,12$ e 18 horas) durante três minutos, com aspersão automatizada com vazão de 1800 $\mathrm{cm}^{3} \min ^{-1}$.

As variáveis avaliadas após 90 dias da instalação do experimento foram: estacas sobreviventes $(\%)$, determinada contando-se o número de estacas vivas, sendo consideradas estacas vivas aquelas que apresentavam brotos e/ou raízes; estacas enraizadas; número de brotos; número de folhas; massa fresca e massa seca da parte aérea e das raízes (g). Para determinação da massa seca da parte aérea e das raízes, foram colocadas em sacos de papel e colocados em estufa a $65^{\circ} \mathrm{C}$ por 72 horas, até atingir o peso constante, pesando-se novamente para obter a massa seca.

Cultura Agronômica, Ilha Solteira, v.26, n.3, p.347-361, 2017 
O delineamento experimental utilizado foi inteiramente casualizado, em esquema fatorial 3 x 3 (tipos de estacas x substratos) totalizando 9 tratamentos com 3 repetições, sendo que cada unidade experimental foi composta por 10 estacas. Os dados de porcentagem de estacas vivas e de enraizamento das estacas foram transformados em arcsen $\sqrt{\left(\frac{x}{100}\right)}$, e os dados de número de brotos e folhas em $\sqrt{(x+0,5)}$. Para efeito de comparação de época foi realizada análise conjunta. Os dados coletados foram submetidos à análise de variância e as médias foram comparadas pelo teste Tukey ao nível de 5\% de significância, utilizando-se o programa SANEST.

\section{RESULTADOS E DISCUSSÃO}

Na Tabela 1, verificam-se os quadrados médios e os níveis de significância dos fatores estudados nas duas épocas para as variáveis: porcentagem de estacas sobreviventes, porcentagem de estacas enraizadas, número de broto, número de folhas e massa fresca e massa seca das folhas e das raízes.

Tabela 1. Quadrado médio e níveis de significância de porcentagem de estacas sobreviventes $(\% \mathrm{ES})$, porcentagem de estacas enraizadas (\%ER), números de brotos $\left(\mathrm{N}^{\circ} \mathrm{B}\right)$, número de folhas $\left(\mathrm{N}^{\circ} \mathrm{F}\right)$, massa fresca da parte aérea (MFPA), massa seca da parte aérea (MSPA), massa fresca da raiz (MFR) e massa seca da raiz (MSR) de pinhão manso (Jatropha curcas L.) em duas épocas. Ilha Solteira - SP, 2012.

\begin{tabular}{|c|c|c|c|c|c|c|c|c|}
\hline \multicolumn{9}{|c|}{$1^{a}$ Época (agosto) } \\
\hline $\begin{array}{l}\text { Causa de } \\
\text { Variação }\end{array}$ & $\begin{array}{l}\mathrm{EV} \\
(\%)\end{array}$ & $\begin{array}{l}\mathrm{ER} \\
(\%)\end{array}$ & NB & NF & $\begin{array}{c}\text { MFPA } \\
(\mathrm{g})\end{array}$ & $\begin{array}{c}\text { MSPA } \\
(\mathrm{g})\end{array}$ & $\begin{array}{c}\text { MFR } \\
(\mathrm{g})\end{array}$ & $\begin{array}{c}\text { MSR } \\
(\mathrm{g})\end{array}$ \\
\hline Estaca (E) & $63,1^{\mathrm{ns}}$ & $425,2^{*}$ & $0,26^{* *}$ & $10,62^{* * *}$ & $152,68^{* *}$ & $4,40^{* *}$ & $6,9^{\text {ns }}$ & $0,1^{\mathrm{ns}}$ \\
\hline Substrato (S) & $667,8^{\text {ns }}$ & $52,1^{\mathrm{ns}}$ & $0,009^{\text {ns }}$ & $0,27^{\mathrm{ns}}$ & $106,76^{*}$ & $3,36^{\mathrm{ns}}$ & $28,8^{*}$ & $0,33^{*}$ \\
\hline$E^{*} S$ & $112,0^{\mathrm{ns}}$ & $219,1^{\mathrm{ns}}$ & $0,035^{\mathrm{ns}}$ & $1,06^{\mathrm{ns}}$ & $7,87^{\mathrm{ns}}$ & $0,28^{\mathrm{ns}}$ & $13,5^{\mathrm{ns}}$ & $0,2^{\mathrm{ns}}$ \\
\hline C.V. $(\%)$ & 26,25 & 24,40 & 8,78 & 13,28 & 49,79 & 57,88 & 65,05 & 77,68 \\
\hline Média Geral & 55,85 & 41,00 & 1,68 & 2,75 & 9,71 & 1,75 & 3,39 & 0,38 \\
\hline \multicolumn{9}{|c|}{ 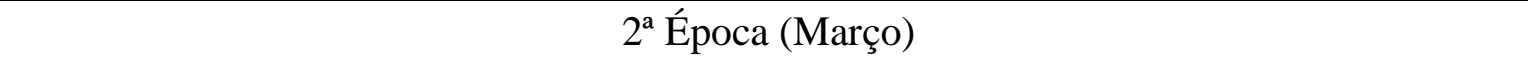 } \\
\hline Estaca (E) & $721,0^{* * *}$ & $663,9^{* *}$ & $0,18^{\mathrm{ns}}$ & $0,94^{* *}$ & $141,3^{* *}$ & $6,02^{* *}$ & $14,6^{*}$ & $0,5^{* *}$ \\
\hline Substrato (S) & $97,6^{*}$ & $46,7^{\mathrm{ns}}$ & $0,12^{\mathrm{ns}}$ & $0,39^{\mathrm{ns}}$ & $32,97^{\mathrm{ns}}$ & $1,07^{\mathrm{ns}}$ & $3,6^{\mathrm{ns}}$ & $0,51^{*}$ \\
\hline$E^{*} S$ & $172,1^{* *}$ & $218,8^{* *}$ & $0,13^{\mathrm{ns}}$ & $0,26^{\mathrm{ns}}$ & $26,56^{\mathrm{ns}}$ & $1,43^{*}$ & $15,0^{*}$ & $0,4^{* *}$ \\
\hline C.V. $(\%)$ & 14,62 & 22,59 & 12,89 & 12,76 & 39,00 & 48,31 & 58,45 & 58,55 \\
\hline Média Geral & 32,50 & 30,39 & 2,90 & 2,81 & 7,85 & 1,43 & 3,27 & 0,52 \\
\hline
\end{tabular}


Na primeira época, houve resultados significativos para as variáveis porcentagens de estacas enraizadas, número de brotos, número de folhas e massa fresca e seca da parte aérea para tipo de estacas; e para o fator substrato, as variáveis massa fresca da parte aérea e massa seca e fresca das raízes apresentaram resultados significativos. Não houve resultados significativos para a interação entre os fatores nas variáveis estudadas.

Para a segunda época estudada, o fator estaca não apresentou resultados significativos para o número de broto; já para substrato as variáveis porcentagem de estacas sobreviventes e massa seca da raiz apresentaram resultados significativos. A interação entre estacas e substratos apresentaram resultados significativos para porcentagem de estacas sobreviventes, massa fresca da parte aérea e massa fresca e seca das raízes.

Na Tabela 2, na qual constam as médias das duas épocas avaliadas em relação à porcentagem de estacas sobreviventes, observa-se que para primeira época (agosto) não houve diferença estatística tanto para tipo de estacas quanto para tipo de substrato utilizado. Em contrapartida, quando a estaquia foi realizada em março houve diferença estatística para a interação entre os fatores, onde a combinação da estaca basal com uso de vermiculita proporcionou $60,14 \%$ de estacas sobreviventes.

Tabela 2. Porcentagem de estacas sobreviventes de pinhão manso (Jatropha curcas L.) submetidas a diferentes substratos em duas épocas. Ilha Solteira - SP, 2012.

\begin{tabular}{|c|c|c|c|c|}
\hline \multicolumn{5}{|c|}{$\begin{array}{l}\text { Porcentagem de Estacas Sobreviventes } \\
\qquad 1^{\mathrm{a}} \text { Época (agosto) }\end{array}$} \\
\hline \multirow{2}{*}{ Substratos } & \multicolumn{3}{|c|}{ Estaca } & \multirow[b]{2}{*}{ Média Gera } \\
\hline & Apical & Mediana & Basal & \\
\hline Areia & $58,55^{\mathrm{ns}}$ & $50,00^{\mathrm{ns}}$ & $46,64^{\mathrm{ns}}$ & $51,74^{\mathrm{ns}}$ \\
\hline Vermiculita & $71,58^{\mathrm{ns}}$ & $84,64^{\mathrm{ns}}$ & $76,82^{\mathrm{ns}}$ & $77,92^{\mathrm{ns}}$ \\
\hline Comercial & $60,14^{\mathrm{ns}}$ & $77,73^{\text {ns }}$ & $83,64^{\mathrm{ns}}$ & $74,34^{\mathrm{ns}}$ \\
\hline Média Geral & $63,53^{\mathrm{ns}}$ & $71,73^{\text {ns }}$ & $70,03^{\mathrm{ns}}$ & \\
\hline \multicolumn{5}{|c|}{ 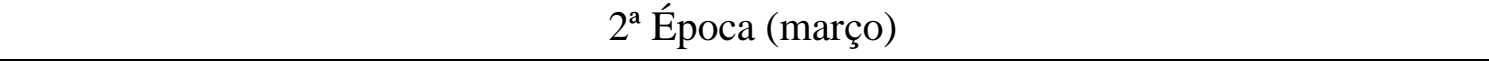 } \\
\hline \multirow{2}{*}{ Substratos } & \multicolumn{3}{|c|}{ Estaca } & \\
\hline & Apical & Mediana & Basal & Média Geral \\
\hline Areia & $10,00 \mathrm{bB}$ & $26,19 \mathrm{aA}$ & $36,45 \mathrm{aB}$ & $23,19^{\mathrm{ns}}$ \\
\hline Vermiculita & $13,01 \mathrm{cB}$ & $30,00 \mathrm{bA}$ & $60,14 \mathrm{aA}$ & $33,69^{\mathrm{ns}}$ \\
\hline Comercial & $33,25 \mathrm{abA}$ & $20,00 \mathrm{bA}$ & $39,85 \mathrm{aB}$ & $30,69^{\mathrm{ns}}$ \\
\hline Média Geral & $17,77^{\mathrm{ns}}$ & $25,28^{\mathrm{ns}}$ & $45,43^{\mathrm{ns}}$ & \\
\hline
\end{tabular}

Médias seguidas de letras distintas minúscula na coluna e maiúscula na linha diferem entre si pelo teste Tukey a $5 \%$ de probabilidade.

Segundo Arruda et al. (2004) para o êxito do plantio as estacas de pinhão manso devem ser retiradas dos ramos mais próximos da base do caule, ladrões ou rebentões, sendo preferidos os ramos não muito grossos, retos, de entrenós curtos, casca lisa, acinzentadas e brilhantes, concordando com os resultados obtidos na segunda época deste trabalho. Por outro 
lado, Fachinello et al. (2005) e Hartmann et al. (2004), citam que estacas herbáceas por terem regiões de constante atividade metabólica e de crescimento contínuo são geralmente estacas que possuem índices de sobrevivência superior às estacas lenhosas, quando não se utiliza regulador vegetal, resultados opostos ao encontrado no presente trabalho.

Em relação à porcentagem de enraizamento, na primeira época, houve diferença significativa apenas para o tipo de estacas (Tabela 3), sendo que a estaca basal a que proporcionou maior porcentagem $(56,95 \%)$, diferindo estatisticamente da estaca apical $(33,71 \%)$. Na segunda época, a interação entre o tipo de estacas e substratos diferiram estatisticamente e a combinação da estaca basal com vermiculita proporcionou o maior enraizamento $(53,35 \%)$.

Tabela 3. Porcentagem de estacas enraizadas de pinhão manso (Jatropha curcas L.) submetidas a diferentes substratos em duas épocas. Ilha Solteira - SP, 2012.

\begin{tabular}{|c|c|c|c|c|}
\hline \multicolumn{5}{|c|}{$\begin{array}{l}\text { Porcentagem de Estacas Enraizadas } \\
\qquad 1^{\mathrm{a}} \text { Época (agosto) }\end{array}$} \\
\hline \multirow{2}{*}{ Substratos } & \multicolumn{3}{|c|}{ Estaca } & \multirow[b]{2}{*}{ Média Geral } \\
\hline & Apical & Mediana & Basal & \\
\hline Areia & $43,16^{\mathrm{ns}}$ & $36,59^{\mathrm{ns}}$ & $39,59^{\mathrm{ns}}$ & $39,68^{\mathrm{ns}}$ \\
\hline Vermiculita & $39,35^{\mathrm{ns}}$ & $33,25^{\mathrm{ns}}$ & $70,33^{\mathrm{ns}}$ & $47,71^{\mathrm{ns}}$ \\
\hline Comercial & $20,00^{\mathrm{ns}}$ & $46,64^{\mathrm{ns}}$ & $60,64^{\mathrm{ns}}$ & $41,76^{\mathrm{ns}}$ \\
\hline Média Geral & $33,71 \mathrm{~B}$ & $38,76 \mathrm{AB}$ & $56,95 \mathrm{~A}$ & \\
\hline \multicolumn{5}{|c|}{$2^{\mathrm{a}}$ Época (março) } \\
\hline \multirow{2}{*}{ Substratos } & \multicolumn{3}{|c|}{ Estaca } & \multirow[b]{2}{*}{ Média Geral } \\
\hline & Apical & Mediana & Basal & \\
\hline Areia & $10,00 \mathrm{bB}$ & $22,15 \mathrm{abA}$ & $36,45 \mathrm{aA}$ & $21,87^{\mathrm{ns}}$ \\
\hline Vermiculita & $6,69 \mathrm{cB}$ & $26,51 \mathrm{bA}$ & $53,35 \mathrm{aA}$ & $26,48^{\mathrm{ns}}$ \\
\hline Comercial & $33,25 \mathrm{aA}$ & $20,00 \mathrm{aA}$ & $33,25 \mathrm{aA}$ & $28,60^{\mathrm{ns}}$ \\
\hline Média Geral & $15,12^{\mathrm{ns}}$ & $22,83^{\mathrm{ns}}$ & $40,90^{\mathrm{ns}}$ & \\
\hline
\end{tabular}

Médias seguidas de letras distintas minúscula na linha e maiúscula na coluna diferem entre si pelo teste Tukey a $5 \%$ de probabilidade.

Estes resultados estão de acordo com Arruda et al. (2004) que obtiveram maiores valores de enraizamento de estacas de pinhão manso, quando utilizaram estacas colhidas de ramos lenhosos, localizados na base dos ramos. Sabe-se que existem diferenças marcantes na composição química da base ao ápice dos ramos e, assim, são observadas variações na formação de raízes de estacas feitas de diferentes partes dos mesmos (OLIVEIRA et al., 2001). Estudos realizados por Noor Camellia et al. (2009), em um experimento na Malásia onde testaram a propagação de pinhão manso em areia no período de julho a setembro, obtiveram $79 \%$ de enraizamento quando utilizaram estacas herbáceas tratadas com $10.000 \mathrm{mg}$ $\mathrm{L}^{-1}$ de AIB. 
Pela análise conjunta, o período do ano interferiu na sobrevivência das estacas e no processo de enraizamento podendo afirmar que a estaquia realizada em agosto proporcionou maiores porcentagem de estacas vivas e enraizadas diferindo estatisticamente da estaquia realizada em março. Segundo Simonetto (1990) a época do ano está estreitamente relacionada com a consistência da estaca, onde estacas herbáceas têm maior capacidade de enraizamento. Estacas coletadas no período de crescimento vegetativo intenso (primavera/verão) tornam-se mais herbáceas, enquanto estacas coletadas no inverno (período de repouso vegetativo ou dormência) possuem maior grau de lignificação e tendem a enraizar menos (FACHINELLO et al., 1995; HARTMANN et al. 1990).

De acordo com Kochlar et al. (2008) os ramos começaram a produzir auxinas que se moveram para baixo, se acumularam na parte inferior da estaca de pinhão manso, e promoveram a formação de raízes. Segundo Fachinello et al. (2005) as estacas lenhosas são mais lignificadas e apresentaram maior potencial de enraizamento devido apresentar nessa região maior teor de carboidratos. Por outro lado, Hartmann et al. (2004) relataram que as estacas caulinares colhidas da posição apical do ramo têm menor grau de lignificação, células meristemáticas com metabolismo mais ativo e ausência ou menor quantidade de compostos fenólicos, o que facilita o enraizamento e a brotação. Os mesmos autores relataram também que outro fator que influencia a capacidade de enraizamento das estacas é o teor de carboidratos visto que, ao longo do ramo, seu teor, tal como a quantidade de substâncias inibidoras ou promotoras do enraizamento, tem variações, constituindo, assim, um dos motivos pelos quais as estacas colhidas de diferentes porções do ramo tendem a diferir quanto ao potencial de enraizamento.

Para número de brotos por estaca, observa-se na Tabela 4 que houve diferença significativa apenas para os tipos de estacas para a primeira época, sendo a basal que proporcionou maior valor $(2,93)$, diferindo da estaca apical $(1,76)$, contudo na segunda época não houve diferença estatísticas para os fatores estudados. Estes resultados concordam com resultados obtidos por Severino et al. (2011) que obtiveram maior número de brotos $(5,7)$ com uso de estaca da base do ramo de pinhão manso diferenciando estatisticamente da estaca apical $(2,3)$. Segundo os mesmos autores o número de brotos e folhas são maiores em estacas oriundas da parte basal e são características relacionadas com o estabelecimento inicial da planta. Segundo Gosh e Singh (2010) estacas da base do ramo também originaram plantas de pinhão manso com maiores números de brotos e raízes. Já Lima et al. (2010) verificaram em estacas de pinhão manso que o número de brotações aumentou linearmente de acordo com o incremento no comprimento das estacas, notando-se 3 brotos nas estacas com $10 \mathrm{~cm}$ e 5 brotos nas de $25 \mathrm{~cm}$ de comprimento. Os resultados encontrados no experimento podem ser explicados pelo fato das estacas basais e medianas apresentarem maior quantidade de reservas para o desenvolvimento de brotos. 
Tabela 4. Número médio de brotos por estacas de pinhão manso (Jatropha curcas L.) submetidas a diferentes substratos em duas épocas. Ilha Solteira - SP, 2012.

\begin{tabular}{|c|c|c|c|c|}
\hline \multicolumn{5}{|c|}{$\begin{array}{l}\text { Número de Brotos } \\
1^{\text {a Época (agosto) }}\end{array}$} \\
\hline \multirow{2}{*}{ Substratos } & \multicolumn{3}{|c|}{ Estaca } & \multirow[b]{2}{*}{ Média Geral } \\
\hline & Apical & Mediana & Basal & \\
\hline Areia & $1,81^{\mathrm{ns}}$ & $2,29^{\mathrm{ns}}$ & $3,32^{\text {ns }}$ & $2,44^{\mathrm{ns}}$ \\
\hline Vermiculita & $1,91^{\mathrm{ns}}$ & $2,01^{\mathrm{ns}}$ & $3,00^{\mathrm{ns}}$ & $2,28^{\mathrm{ns}}$ \\
\hline Comercial & $1,58^{\mathrm{ns}}$ & $2,71^{\mathrm{ns}}$ & $2,49^{\mathrm{ns}}$ & $2,23^{\mathrm{ns}}$ \\
\hline Média Geral & $1,76 \mathrm{~B}$ & $2,33 \mathrm{AB}$ & $2,93 \mathrm{~A}$ & \\
\hline \multicolumn{5}{|c|}{$2^{\mathrm{a}}$ Época (março) } \\
\hline \multirow{2}{*}{ Substratos } & \multicolumn{3}{|c|}{ Estaca } & \\
\hline & Apical & Mediana & Basal & Média Geral \\
\hline Areia & $2,87^{\mathrm{ns}}$ & $1,94^{\mathrm{ns}}$ & $3,92^{\text {ns }}$ & $2,86^{\mathrm{ns}}$ \\
\hline Vermiculita & $2,64^{\mathrm{ns}}$ & $4,57^{\mathrm{ns}}$ & $3,96^{\mathrm{ns}}$ & $3,68^{\mathrm{ns}}$ \\
\hline Comercial & $2,60^{\mathrm{ns}}$ & $2,72^{\mathrm{ns}}$ & $3,43^{\mathrm{ns}}$ & $2,91^{\mathrm{ns}}$ \\
\hline Média Geral & $2,70^{\mathrm{ns}}$ & $2,99^{\mathrm{ns}}$ & $3,77^{\mathrm{ns}}$ & \\
\hline
\end{tabular}

Médias seguidas de letras distintas minúscula na linha e maiúscula na coluna diferem entre si pelo teste Tukey a $5 \%$ de probabilidade.

Tabela 5. Média de números de folhas por estaca de pinhão manso (Jatropha curcas L.) submetidas a substratos em duas épocas. Ilha Solteira - SP, 2012.

\begin{tabular}{|c|c|c|c|c|}
\hline \multicolumn{5}{|c|}{$\begin{array}{l}\text { Números de Folhas } \\
1^{\mathrm{a}} \text { Época (agosto) }\end{array}$} \\
\hline \multirow{2}{*}{ Substratos } & \multicolumn{3}{|c|}{ Estaca } & \multirow[b]{2}{*}{ Média Geral } \\
\hline & Apical & Mediana & Basal & \\
\hline Areia & $4,70^{\mathrm{ns}}$ & $6,62^{\mathrm{ns}}$ & $8,01^{\mathrm{ns}}$ & $6,38^{\text {ns }}$ \\
\hline Vermiculita & $5,36^{\mathrm{ns}}$ & $5,68^{\mathrm{ns}}$ & $9,33^{\mathrm{ns}}$ & $6,68^{\mathrm{ns}}$ \\
\hline Comercial & $4,66^{\mathrm{ns}}$ & $9,16^{\mathrm{ns}}$ & $11,56^{\mathrm{ns}}$ & $8,21^{\mathrm{ns}}$ \\
\hline Média Geral & $4,90 \mathrm{~B}$ & $7,08 \mathrm{AB}$ & $9,58 \mathrm{~A}$ & \\
\hline \multicolumn{5}{|c|}{$2^{\mathrm{a}}$ Época (março) } \\
\hline \multirow{2}{*}{ Substratos } & \multicolumn{3}{|c|}{ Estaca } & \\
\hline & Apical & Mediana & Basal & Média Geral \\
\hline Areia & $4,90^{\mathrm{ns}}$ & $5,45^{\mathrm{ns}}$ & $8,16^{\mathrm{ns}}$ & $6,10^{\mathrm{ns}}$ \\
\hline Vermiculita & $5,29^{\mathrm{ns}}$ & $9,68^{\mathrm{ns}}$ & $9,76^{\mathrm{ns}}$ & $8,10^{\mathrm{ns}}$ \\
\hline Comercial & $7,86^{\mathrm{ns}}$ & $5,89^{\mathrm{ns}}$ & $10,81^{\mathrm{ns}}$ & $8,07^{\mathrm{ns}}$ \\
\hline Média Geral & $5,95 \mathrm{~B}$ & $6,89 \mathrm{~B}$ & $9,55 \mathrm{~A}$ & \\
\hline
\end{tabular}

Médias seguidas de letras distintas minúscula na linha e maiúscula na coluna diferem entre si pelo teste Tukey a $5 \%$ de probabilidade.

Cultura Agronômica, Ilha Solteira, v.26, n.3, p.347-361, 2017 
Com relação ao número de folhas, observa-se na Tabela 5, que houve diferença significativa apenas para tipos de estacas para as duas épocas, sendo que a estaca basal na primeira época proporcionou maiores valores $(9,58)$ diferindo da estaca apical $(4,90)$, obtendo com a estaca basal um número médio de 9,55 folhas, diferindo estatisticamente da estaca mediana $(6,89)$ e apical $(5,95)$ na segunda época. Estudos realizados por Araújo et al. (2009) testando a consistência do ramo no enraizamento de mini estacas de pinhão manso com e sem AIB, obtiveram maiores números de folhas sem o uso do regulador para a estaca lenhosa, com média de 23,47 folhas, valor esse maior que o encontrado no presente trabalho.

A importância do maior número de folhas na cultura do pinhão manso, é devido as brotações serem formadas anteriormente as raízes, e isso ocorre, devido à presença de reserva de carboidratos que influenciam a produção de auxinas, quando o pinhão manso é propagado pelo método da estaquia (BARBOSA et al., 2011). Dessa forma, o número de folhas e brotos podem ser um parâmetro para o sucesso do enraizamento de estacas de pinhão-manso (KUMAR et al., 2011), já que o enraizamento adventício é conhecido como um dos maiores problemas da propagação. Segundo Hartmann et al. (2004) as folhas e as gemas produzem auxinas e os carboidratos translocados das folhas são importantes para a formação e desenvolvimento das raízes.

Tabela 6. Média em gramas de massa fresca da parte aérea por estacas de pinhão manso (Jatropha curcas L.) submetidas a substratos em duas épocas. Ilha Solteira - SP, 2012.

\begin{tabular}{|c|c|c|c|c|}
\hline \multicolumn{5}{|c|}{$\begin{array}{l}\text { Massa Fresca da Parte Aérea (g) } \\
1^{\text {a Época (agosto) }}\end{array}$} \\
\hline \multirow{2}{*}{ Substratos } & \multicolumn{3}{|c|}{ Estaca } & \multirow[b]{2}{*}{ Média Gera } \\
\hline & Apical & Mediana & Basal & \\
\hline Areia & $5,01^{\mathrm{ns}}$ & $7,48^{\text {ns }}$ & $10,62^{\mathrm{ns}}$ & $7,70 \mathrm{~b}$ \\
\hline Vermiculita & $5,07^{\mathrm{ns}}$ & $5,91^{\mathrm{ns}}$ & $12,23^{\mathrm{ns}}$ & $7,74 b$ \\
\hline Comercial & $9,37^{\mathrm{ns}}$ & $11,48^{\mathrm{ns}}$ & $20,20^{\mathrm{ns}}$ & $13,68 \mathrm{a}$ \\
\hline Média Geral & $6,48 \mathrm{~B}$ & $8,29 \mathrm{~B}$ & $14,35 \mathrm{~A}$ & \\
\hline \multicolumn{5}{|c|}{$2^{\mathrm{a}}$ Época (março) } \\
\hline \multirow{2}{*}{ Substratos } & \multicolumn{3}{|c|}{ Estaca } & \multirow[b]{2}{*}{ Média Geral } \\
\hline & Apical & Mediana & Basal & \\
\hline Areia & $4,52^{\mathrm{ns}}$ & $5,45^{\mathrm{ns}}$ & $11,61^{\mathrm{ns}}$ & $7,19^{\mathrm{ns}}$ \\
\hline Vermiculita & $1,73^{\mathrm{ns}}$ & $8,21^{\mathrm{ns}}$ & $9,14^{\mathrm{ns}}$ & $6,36^{\mathrm{ns}}$ \\
\hline Comercial & $8,67^{\mathrm{ns}}$ & $5,00^{\mathrm{ns}}$ & $16,37^{\mathrm{ns}}$ & $10,01^{\mathrm{ns}}$ \\
\hline Média Geral & $4,97 \mathrm{~B}$ & $6,22 \mathrm{~B}$ & $12,37 \mathrm{~A}$ & \\
\hline
\end{tabular}

Médias seguidas de letras distintas minúscula na linha e maiúscula na coluna diferem entre si pelo teste Tukey a $5 \%$ de probabilidade. 
A Tabela 6, demonstra que houve diferença significativa para substratos apenas em relação à primeira época, nesse caso o substrato comercial proporcionou maiores médias de massa fresca $(13,68 \mathrm{~g})$ diferenciando-se estatisticamente dos demais substratos.

Os maiores valores observados para massa fresca da parte aérea quando se utilizou estacas basais pode estar relacionado com o maior número de folhas que as estacas basais apresentaram (Tabela 5).

A estaca basal na primeira época apresentou maior valor $(2,54 \mathrm{~g})$ diferindo estatisticamente da estaca apical $(1,21 \mathrm{~g})$ (Tabela 7). Na segunda época, com o desdobramento da interação entre o tipo de estaca e os substratos, pode-se observar que a estaca basal e o substrato comercial proporcionaram maiores valores para a massa fresca da parte aérea $(3,15$ g).

Tabela 7. Média em grama de massa seca da parte aérea de estacas de pinhão manso (Jatropha curcas L.) submetidas a substratos em duas épocas. Ilha Solteira - SP, 2012.

\begin{tabular}{|c|c|c|c|c|}
\hline \multicolumn{5}{|c|}{$\begin{array}{c}\text { Massa Seca da Parte Aérea (g) } \\
1^{\mathrm{a}} \text { Época (agosto) }\end{array}$} \\
\hline \multirow{2}{*}{ Substratos } & \multicolumn{3}{|c|}{ Estaca } & \multirow[b]{2}{*}{ Média Gera } \\
\hline & Apical & Mediana & Basal & \\
\hline Areia & $0,79^{\mathrm{ns}}$ & $1,37^{\mathrm{ns}}$ & $1,77^{\mathrm{ns}}$ & $2,45^{\mathrm{ns}}$ \\
\hline Vermiculita & $1,09^{\mathrm{ns}}$ & $1,06^{\mathrm{ns}}$ & $2,33^{\mathrm{ns}}$ & $1,49^{\mathrm{ns}}$ \\
\hline Comercial & $1,77^{\mathrm{ns}}$ & $2,05^{\mathrm{ns}}$ & $3,52^{\mathrm{ns}}$ & $2,45^{\mathrm{ns}}$ \\
\hline Média Geral & $1,21 \mathrm{~B}$ & $1,49 \mathrm{AB}$ & $2,54 \mathrm{~A}$ & \\
\hline \multicolumn{5}{|c|}{$2^{\mathrm{a}}$ Época (março) } \\
\hline \multirow{2}{*}{ Substratos } & \multicolumn{3}{|c|}{ Estaca } & \\
\hline & Apical & Mediana & Basal & Média Geral \\
\hline Areia & $0,59 \mathrm{bA}$ & $1,14 \mathrm{abA}$ & $2,26 \mathrm{aAB}$ & $1,33^{\mathrm{ns}}$ \\
\hline Vermiculita & $0,23 \mathrm{aA}$ & $1,53 \mathrm{aA}$ & $1,67 \mathrm{aB}$ & $1,14^{\mathrm{ns}}$ \\
\hline Comercial & $1,66 \mathrm{bA}$ & $0,62 \mathrm{bA}$ & $3,15 \mathrm{aA}$ & $1,81^{\mathrm{ns}}$ \\
\hline Média Geral & $0,82^{\mathrm{ns}}$ & $1,10^{\mathrm{ns}}$ & $2,36^{\mathrm{ns}}$ & \\
\hline
\end{tabular}

Médias seguidas de letras distintas minúscula na linha e maiúscula na coluna diferem entre si pelo teste Tukey a $5 \%$ de probabilidade.

Estes resultados estão de acordo com Severino et al. (2011), que ao testarem tipos de estacas para propagação do pinhão manso, também observaram que estacas basais proporcionaram valores maiores para massa seca da parte aérea $(10,1 \mathrm{~g})$ e massa seca da raiz $(0,47 \mathrm{~g})$. Estudos realizados por Vazquez et al. (2010) testando comprimento e posição do ramo, mostraram que estacas basais com $90 \mathrm{~cm}$ de comprimento proporcionaram maiores massa seca da parte aérea $(17,68 \mathrm{~g})$ diferindo estatisticamente das estacas apicais com $90 \mathrm{~cm}$ $(7,46 \mathrm{~g})$. O mesmo ocorreu quando utilizaram estacas basais com $30 \mathrm{~cm}$ de comprimento $(6,92 \mathrm{~g})$, onde diferiu estatisticamente da estaca apical com $30 \mathrm{~cm}$ de comprimento $(1,89 \mathrm{~g})$.

Cultura Agronômica, Ilha Solteira, v.26, n.3, p.347-361, 2017 
Lima et al. (2011) não obtiveram resultados significativos para massa seca de mudas de pinhão manso cultivadas em substratos compostos por misturas de casca de mamona. Por outro lado, Lima et al. (2010) observaram em mudas de pinhão manso, o valor de massa seca da parte aérea com aproximadamente $7 \mathrm{~g}$ em estaca de $23 \mathrm{~cm}$ de comprimento, diminuindo o valor conforme aumentou o comprimento da estaca.

As características ideais de um substrato dependem das exigências da espécie cultivada, por isso dificilmente se encontra um material que reúna sozinho todas as condições nutricionais e físicas para o adequado crescimento das plantas (LIMA et al., 2006; LIMA et al., 2009).

Para massa fresca das raízes (Tabela 8), a primeira época proporcionou resultados significativos para substrato, onde o comercial obteve maior valor $(5,44 \mathrm{~g})$ diferindo estatisticamente da vermiculita $(2,13 \mathrm{~g})$ e da areia $(2,60 \mathrm{~g})$. Estes resultados podem ter ocorrido devido o substrato comercial ser um produto resultante da combinação de adubos químicos NPK + micronutrientes, vermiculita, casca de pinus, fibra de coco, podendo assim proporcionar um melhor desenvolvimento das raízes.

Tabela 8. Média em gramas de massa fresca de raízes de estacas de pinhão manso (Jatropha curcas L.) submetidas a substratos em duas épocas. Ilha Solteira - SP, 2012.

\begin{tabular}{|c|c|c|c|c|}
\hline \multicolumn{5}{|c|}{$\begin{array}{c}\text { Massa Fresca de Raízes (g) } \\
1^{\text {a Época (agosto) }}\end{array}$} \\
\hline \multirow{2}{*}{ Substratos } & \multicolumn{3}{|c|}{ Estaca } & \multirow[b]{2}{*}{ Média Geral } \\
\hline & Apical & Mediana & Basal & \\
\hline Areia & $2,08^{\mathrm{ns}}$ & $2,66^{\mathrm{ns}}$ & $3,08^{\mathrm{ns}}$ & $2,60 \mathrm{~b}$ \\
\hline Vermiculita & $0,98^{\mathrm{ns}}$ & $1,88^{\mathrm{ns}}$ & $3,54^{\mathrm{ns}}$ & $2,13 b$ \\
\hline Comercial & $8,69^{\mathrm{ns}}$ & $2,60^{\mathrm{ns}}$ & $5,04^{\mathrm{ns}}$ & $5,44 \mathrm{a}$ \\
\hline Média Geral & $3,91^{\mathrm{ns}}$ & $2,38^{\mathrm{ns}}$ & $3,88^{\mathrm{ns}}$ & \\
\hline \multicolumn{5}{|c|}{$2^{\mathrm{a}}$ Época (março) } \\
\hline \multirow{2}{*}{ Substratos } & \multicolumn{3}{|c|}{ Estaca } & \\
\hline & Apical & Mediana & Basal & Média Geral \\
\hline Areia & $1,63 \mathrm{bA}$ & $3,03 \mathrm{abAB}$ & $6,77 \mathrm{aA}$ & $3,81^{\mathrm{ns}}$ \\
\hline Vermiculita & $1,03 \mathrm{bA}$ & $5,29 \mathrm{aA}$ & 4,01abA & $3,44^{\mathrm{ns}}$ \\
\hline Comercial & $3,88 \mathrm{aA}$ & $0,58 \mathrm{aB}$ & $3,24 \mathrm{aA}$ & $2,57^{\mathrm{ns}}$ \\
\hline Média Geral & $2,18^{\mathrm{ns}}$ & $2,97^{\mathrm{ns}}$ & $4,68^{\mathrm{ns}}$ & \\
\hline
\end{tabular}

Médias seguidas de letras distintas minúscula na linha e maiúscula na coluna diferem entre si pelo teste Tukey a $5 \%$ de probabilidade.

Estudos realizados por Camargo et al. (2011), onde avaliaram substratos para produção de mudas de pinhão manso aos noventa dias após a instalação do ensaio, verificaram, que quando utilizou como substrato esterco bovino, a massa seca da raiz foi 5,5 g. Para produção de mudas de pinhão-manso, Paulino et al. (2011) constataram que as propriedades físicas do substrato são essenciais para o pleno desenvolvimento das mudas, pois o cultivo de plantas 
em recipientes limita o desenvolvimento do sistema radicular, influenciando diretamente na absorção de água e nutrientes.

As pesquisas com o pinhão manso ainda são incipientes e pouco se conhece, principalmente em relação aos métodos propagativos. Contudo, Smiderle e Kroetz (2009) constataram que a utilização de estacas lenhosas desenvolve melhor o sistema radicular, sendo o mesmo verificado por Kockhar et al. (2008) e Noor Camellia et al. (2009), em comparação às estacas semilenhosas e herbáceas.

Com relação à massa seca das raízes (Tabela 9) o fator substrato na primeira época apresentou resultado significativo, onde o comercial $(0,50 \mathrm{~g})$ diferiu estatisticamente da vermiculita $(0,23 \mathrm{~g})$. Na segunda época o desdobramento da interação entre os tipos de estacas e substratos mostrou que a estaca basal no substrato areia apresentou maior valor $(1,45 \mathrm{~g})$. Segundo Lima et al. (2006) a quantidade de raízes é um fator importante para o vigor das plantas.

Tabela 9. Média em gramas de massa seca de raízes de estacas de pinhão manso (Jatropha curcas L.) submetidas a substratos em duas épocas. Ilha Solteira - SP, 2012.

\begin{tabular}{ccccc}
\hline \multicolumn{5}{c}{$\begin{array}{c}\text { Massa Seca de Raízes (g) } \\
1^{\mathrm{a}} \text { Época (agosto) }\end{array}$} \\
\hline \multirow{5}{*}{ Substratos } & Estaca & \\
\cline { 2 - 5 } & Apical & Mediana & Basal & Média Geral \\
\hline Areia & $0,26^{\mathrm{ns}}$ & $0,30^{\mathrm{ns}}$ & $0,35^{\mathrm{ns}}$ & $0,30 \mathrm{ab}$ \\
Vermiculita & $0,11^{\mathrm{ns}}$ & $0,19^{\mathrm{ns}}$ & $0,40^{\mathrm{ns}}$ & $0,23 \mathrm{~b}$ \\
Comercial & $0,99^{\mathrm{ns}}$ & $0,25^{\mathrm{ns}}$ & $0,55^{\mathrm{ns}}$ & $0,50 \mathrm{a}$ \\
\hline Média Geral & $0,45^{\mathrm{ns}}$ & $0,25^{\mathrm{ns}}$ & $0,45^{\mathrm{ns}}$ & \\
\hline \multirow{5}{*}{$2^{\mathrm{a}}$ Época $($ março) } & & \\
\hline Substratos & Estaca & & \\
\cline { 2 - 5 } & $\mathrm{Apical}$ & Mediana & Basal & Média Geral \\
\hline Areia & $0,25 \mathrm{bA}$ & $0,69 \mathrm{bA}$ & $1,45 \mathrm{aA}$ & $0,79^{\mathrm{ns}}$ \\
Vermiculita & $0,13 \mathrm{aA}$ & $0,58 \mathrm{aAB}$ & $0,50 \mathrm{aB}$ & $0,41^{\mathrm{ns}}$ \\
Comercial & $0,56 \mathrm{aA}$ & $0,05 \mathrm{aB}$ & $0,48 \mathrm{aB}$ & $0,36^{\mathrm{ns}}$ \\
\hline Média Geral & $0,31^{\mathrm{ns}}$ & $0,44^{\mathrm{ns}}$ & $0,81^{\mathrm{ns}}$ & \\
\hline
\end{tabular}

Médias seguidas de letras distintas minúscula na linha e maiúscula na coluna diferem entre si pelo teste Tukey a $5 \%$ de probabilidade.

Um dos maiores problemas da propagação na cultura do pinhão manso é a formação de raízes adventícias. Segundo Noor Camellia et al. (2009) o pinhão manso é considerado uma espécie de fácil enraizamento, onde inicia a formação dos primórdios de raízes adventícias a partir do oitavo dia, e estas emergem através da epiderme após o décimo primeiro dia. Severino et al. (2007) verificaram que plantas de pinhão manso propagadas por estacas não desenvolvem um sistema radicular normal, possuindo raízes finas e superficiais, tendo sido observado o mesmo comportamento neste trabalho.

Cultura Agronômica, Ilha Solteira, v.26, n.3, p.347-361, 2017 


\section{CONCLUSÃO}

A estaquia realizada em agosto proporcionou melhores resultados que em março.

O uso de estacas da parte basal do ramo e o uso dos substratos: vermiculita e composto orgânico comercial (Bioplant ${ }^{\circledR}$ ) foram eficientes para produção de mudas de pinhão manso.

\section{AGRADECIMENTOS}

À Petrobrás Biocombustível e Capes pela concessão da bolsa.

\section{REFERÊNCIAS BIBLIOGRÁFICAS}

ARAÚJO, E. C. E.; MERITO FILHO, C. H. A.; AZEVEDO, D. M. P. Interação entre doses de reguladores e consistência do ramo no enraizamento de miniestacas de pinhão-manso. In: CONGRESSO BRASILEIRO DE PESQUISAS DE PINHÃO MANSO 1., 2009, Brasília. Anais... Brasília: Embrapa Agroenergia, 2009. 1 CD-ROM.

ARRUDA, F. P.; BELTRÃO, N. E. M.; ANDRADE, A. P.; PEREIRA, W. E.; SEVERINO, L. S. Cultivo de pinhão manso (Jatropha curcas L.) como alternativa para o semi-árido nordestino. Revista Brasileira de Oleaginosas e Fibrosas, Campina Grande, v. 8, n. 1, p.789-799, 2004.

BARBOSA, A. M.; MARQUES, T. A.; SILVA, I. F.; CATUCHI, T. A.; VITOLO, H. F.; GUIDORIZI, K. A. Propagação de estacas de pinhão manso em função da aplicação de ácido indolbutírico (IBA). Colloquium Agrariae, Presidente Prudente, v. 7, n. especial, p.107-114, 2011

CAMARGO, R.; PIRES, S. C.; MALDONADO, A. C. D.; CARVALHO, H. P; COSTA, T. R. Avaliação de substratos para a produção de mudas de pinhão-manso em sacolas plásticas. Revista Trópica - Ciências Agrárias e Biológicas, Uberlândia, v. 5, n. 1, p.31-38, 2011.

COSTA, T. R.; CAMARGO, R. Produção de mudas de pinhão manso (Jatropha curcas L.) em tubetes a partir de diferentes fontes de matéria orgânica. Revista Horizonte Científico, Uberlândia, v. 3, n. 1, p.1-17, 2009.

FACHINELlO, J. C.; HOFFMANN, A.; NACHTIGAL, J. C. (Ed.). Propagação de plantas frutíferas. Brasília: Embrapa Informação Tecnológica, 2005. 221 p.

FACHINELLO, J. C.; HOFFMANN, A.; NACHTIGAL, J. C.; KERSTEN, E.; FORTES, G. R. L. Propagação de plantas frutíferas de clima temperado. 2. ed. Pelotas: UFPEL, 1995. $179 \mathrm{p}$.

FERNANDES, C.; CORÁ, J. E. Substratos hortículas. Cultivar Hortaliças e Frutas, Pelotas, v. 10, n. 1, p.32-34, 2001.

Cultura Agronômica, Ilha Solteira, v.26, n.3, p.347-361, 2017 
GOSH, L.; SINGH, L. Study of factors influencing vegetative propagation of Jatropha curcas. Indian Forester, Uttarakhand, v. 136, n. 1, p.1637-1648, 2010.

HARTMANN, H. T.; KESTER, D. E.; DAVIES JUNIOR, F. T.; GENEVE, R. L. Plant propagation: principles and practices. 7. ed. New Jersey: Prentice Hall, 2004. 880 p.

HARTAMANN, H. T.; KERSTER, D. E.; DAVIES JUNIOR, F. T.; GENEVE, R. L. Plant propagation: principles and pratices. 6. ed. New Jersey: Prentice Hall, 1997. 770 p.

HARTAMANN, H. T.; KESTER, D. E; DAVIES JUNIOR, F. T. Propagación de plantas: princípios y practicas. México: Campañia Editorial Continental, 1990. 760 p.

KOCHLAR, S.; SING, S. P.; KOCHAR, V. P. Effect of auxins and associated biochemical changes during clonal propagation of the biofuel plant - Jatropha curcas. Biomass and Bioenerg, United Kingdom, v. 32, n. 12, p.1136-1143, 2008.

JANICK, J. A ciência da horticultura. Rio de Janeiro: USAID, 1966. 485 p.

KUMAR, D.; SINGH, S.; SHARMA, R.; KUMAR, V.; CHANDRA, H.; MALHOTRA, K. Above-ground morphological predictors of rooting success in rooted cuttings of Jatropha curcas L. Biomass and Bioenergy, Pergamon, v. 35, n. 9, p.3891-3895, 2011.

LIMA, R. L. S.; SEVERINO, L. S.; FERREIRA, G. B.; SOFIATTIS, V.; SAMPAIO, L. R.; BELTRÃO, N. E. M. Casca de mamona associada a quatro fontes de matéria orgânica para a produção de mudas de pinhão-manso. Revista Ceres, Viçosa, v. 58, n. 2, p.232-237, 2011.

LIMA, R. L. S.; SEVERINO, L. S.; PEREIRA, W. E.; LUCENA, A. M. A.; GHREYI, H. R.; ARRIEL, N. H. C. Comprimento das estacas e parte do ramo para formação de mudas de pinhão-manso. Revista Brasileira de Engenharia Agrícola e Ambiental, Campina Grande, v. 14, n. 11, p.1234-1239, 2010.

LIMA, R. L. S.; SEVERINO, L. S.; SAMPAIO, L. R.; FREIRE, M. A. O.; BELTRÃO, N. E. M.; ARRIEL, N. H. C. Crescimento e teor foliar de nutrientes em mudas de pinhão manso (Jatropha curcas 1.) em substratos contendo cinco materiais orgânicos e fertilizante mineral. Revista Brasileira Oleaginosas e Fibroses, Campina Grande, v. 13, n. 1, p.29-36, 2009.

LIMA, R. L. S.; SEVERINO, L. S.; SILVA, M. I. L.; JERÔNIMO, J. F.; VALE, L. S.; BELTRÃO, N. E. M. Substratos para produção de mudas de mamoneira compostos por misturas de cinco fontes de matéria orgânica. Ciência e Agrotecnologia, Lavras, v. 30, n. 3, p.474-479, 2006.

NOOR CAMELLIA, N. A.; THOHIRAH, L. A.; ABDULLAH, N. A. P.; MOHD KHIDIR, O. Improvement on rooting quality of Jatropha curcas using indole butyric acid (IBA). Research Journal of Agriculture and Biological Sciences, Jordan, v. 5, n. 4, p.338-343, 2009.

NUNES, C. F. Caracterização de frutos, sementes e plântulas e cultivo de embriões de pinhão manso (Jatropha curcas L.). 2007.78 f. Dissertação (Mestrado em Produção Vegetal) - Faculdade de Agronomia, Universidade Federal de Lavras, Lavras, 2007.

Cultura Agronômica, Ilha Solteira, v.26, n.3, p.347-361, 2017 
OLIVEIRA, M. C.; RIBEIRO, J. F.; RIOS, M. N. S.; REZENDE, M. E. Enraizamento de estacas para produção de mudas de espécies nativas de matas de galeria. Brasília: Embrapa Cerrados, 2001. 4 p. (Embrapa Cerrados. Recomendação Técnica, 41).

PAIVA, H. N.; GOMES, J. M. Propagação vegetativa de espécies florestais. Viçosa: Universidade Federal de Viçosa, 2005. 40 p.

PAUlinO, J.; FOLEGATTI, M. V.; FLUMIGNAN, D. L.; ZOLIN, C. A.; BARBOSA JÚNIOR, C. R. A.; PIEDADE, S. M. S. Crescimento e qualidade de mudas de pinhão-manso produzidas em ambiente protegido. Revista Brasileira de Engenharia Agrícola e Ambiental, Campina Grande, v. 15, n. 1, p.3-46, 2011.

SATURNINO, H. M.; PACHECO, D. D.; KAKIDA, J.; TOMINAGA, N.; GONÇALVES, N. P. Cultura do Pinhão manso (Jatropha curcas L.). Produção de oleaginosas para biodiesel. Informe Agropecuário, Belo Horizonte, v. 26, n. 229, p.44-74, 2005.

SEVERINO, L. S.; LIMA, R. L. S.; LUCENA, A. M. A.; FREIRE, M. A. O.; SAMPAIO, L. R.; VERAS, R. P.; MEDEIROS, K. A. A. L.; SOFIATTI, V.; ARRIEL, N. H. C. Propagation by stem cuttings and root system structure of Jatropha curcas. Biomass and Bioenergy, United Kingdom, v. 35, n. 7, p.3160-3166, 2011.

SEVERINO, L. S.; LIMA, R. L. S.; LEÃO, A. B.; BELTRÃO, N. E. M. Formação do sistema radicular de plantas de pinhão manso propagadas por mudas, estacas e sementes. Campina Grande: EMBRAPA-CNPA, 2007. 5 p. (Comunicado Técnico, 348).

SIMONETTO, P. R. Propagação de Pyrus calleryana Dcne e Pyrus betulaefolia bunge, porta enxertos para pereira, através do processo de estaquia. 1990. 59 f. Dissertação (Mestrado em Agronomia) - Faculdade de Agronomia Eliseu Maciel, Universidade Federal de Pelotas, Pelotas, 1990.

SMIDERLE, O. J.; KROETZ, V. J. Produção de mudas de pinhão manso por estaquia em área de cerrado de Roraima. In: CONGRESSO BRASILEIRO DE PESQUISAS DE PINHÃO MANSO, 1., 2009, Brasília. Anais... Brasília-DF: Embrapa Bioenergia, 2009. 1 CD-ROM.

VAZQUEZ, G. H.; LAZARINI, E.; RIBEIRO, T. C.; GRADELA, A. S.; SILVA, T. F.; VIANA, R. L. Produção de mudas de pinhão-manso via estaquia. Revista Brasileira Oleaginosas e Fibroses, Campina Grande, v. 14, n. 3, p.97-105, 2010. 